\title{
Research on Interference of Spatial Construction Mode with Logistics Technology
}

\author{
Zhijuan Jiang \\ Qinzhou University, Qinzhou, 535000, China
}

Keywords: Spatial mode. Logistics economy. Role and effect. Element analysis

\begin{abstract}
With the continuous development of economy currently, the economic exchange between regions has been increasingly frequent and the development scale of domestic and foreign logistics economy is continuously expanding, which, based on the spatial mode and spatial structure, have great effect on the development of logistics economy of China. And the spatial mode has also become the important theoretical basis for the evolution of logistics economy. In combination with the development characteristics of logistics economy and the movement law of spatial logistics economy, the author proposes the theoretical mode appropriate for the development of logistics economy of China, form the spatial operation mode of logistics economy with point-axis-network-plane structure and the joint spatial pattern of driving of the surrounding economic zones by the central developed cities for joint development.
\end{abstract}

\section{Introduction}

With the continuous development of economy, the logistics industry has also been further developed, and many countries take logistics industry as an important industry for development, and China is also without exception. As an emerging industry, the logistics economy can drive the development of regional economy to some extent, but the regions require to organize the economy scientifically and reasonably, so as to activate the regional vitality effectively. The element of logistics element is an basic element of economy, and all social spatial structures should be based on the basic premise of element of logistics economy, and the spatial structural form should also take the spatial configuration as the basic condition. Therefore, in this paper, the main discussion is focused on the development of logistics economy in the spatial construction mode.

\section{Spatial structure and spatial organization}

\section{Spatial structure}

As the result of interplay and interaction between the natural elements and social economy, the regional spatial structures often will present their roles in many natural and social economic forms, thus generating the spatial form, while for all objects, the action strength, aggregation degree and the change of position form spatial structure. The spatial structure must comply with the corresponding evolution law. As some regions have not been developed, the economic element activities in these regions are relatively frequent, and these economic elements will be sure to act and contact with other corresponding elements; in some region, the natural and social economic elements are relatively concentrated, there must be certain relevance and aggregation, in this way, the corresponding natural and social economic objects are formed to a certain extent; further deepening the role between each object can make more regional aggregations appear, so as to generate the corresponding linear regional infrastructures. Generally, the mutual contact and interaction between the basic line, region and point from the basic structure of space; in general, the points will form cities after a long-time development, while the infrastructures of line form will become the aggregation zones of many natural and social economic objects after development of certain stages. After continuous development and expansion, the aggregation scale will gradually become social economic zones, with the complicated relation between social economic zones and cities, the regional structure will also become relatively complicated to a certain extent. 


\section{Spatial organization}

Generally, the scientific and regulated organizations and control can realize the evolution of spatial structure, that is to say, they and control and organize the spatial structures reasonably. For the spatial organization, it is required to comply with the regulations of the role, and take the action method and property of various natural and social economic objects as the basis, and then allocate the regional economic and many other elements reasonably, so as to optimize the spatial structure. Therefore, it is possible to take the spatial structure as the final result for people to make full use of the role of the organization.

\section{Element characteristics and movement rules}

\section{Elements of logistics economy}

Logistics means the whole process to transfer the materials from the suppliers to the demanders, including various links like warehousing, transportation, packing and distribution, and these links will generally involve in various fields such as sales, circulation and production. In general, in the logistics economy activity, these links are a micro unit, composed of relatively specific elements of logistics economy. The elements of logistics economy mean an organic system composed of many element units, which, in the micro level, mainly contain the packing tools, transportation vehicles, relevant information equipment and various loading and unloading tools etc.. Among these elements, transportation tools are the most important; in the macro level, logistics mainly refer to the logistics enterprises, i.e. the main body playing important roles in the whole logistics activity.

\section{Element characteristics}

\section{Mobility}

Mobility means that the basic properties of some elements have a relatively strong flexibility and instability. As these elements are in the essential position, they can make full use of the activation roles to nature, society and many other elements. Therefore, compared with other economic elements, the elements of logistics economy will often move in the regions where they are located, and move among regions. For the elements of logistics economy, mobility is not only the essential characteristics, but is also the basic condition to form other characteristics.

\section{Affinity}

Affinity means that the elements of logistics economy are easy to interplay and interact with nature, society and many other elements, and combine with them in the mutual communication, so as to generate a composition effect. For the elements of logistics economy, such affinity will not only act on the elements of the same substances, but will also act on the heterogenic substances, and the two will contact to combine finally.

\section{Movement rules of elements}

\section{Randomness}

At the very beginning, the regional behaviors of elements of logistics economy will present an aimless mobility, i.e. the resistance behavior presents the characteristic of randomness without certain law, and generally, they will present a scattered state. Although the logistics elements are irregular in distribution, they do not have the characteristics of homogeneity.

\section{Directionality}

For the logistics elements, when moving disorderedly in a region, they will be toward a direction, that is to say, although the logistics elements are of irregular operation in regions, they have the characteristics of directionality.

\section{Spatial organization mode}

\section{Point-axis-network-plane}

Generally, the formation of logistics economy space will have a direct influence on the spatial structure of the region, and organizing the spatial behaviors which the logistics elements have scientifically and reasonably can effectively improve the regional spatial structure and promote the 
development of regional economy. However, according to the current situation of development of logistics economy of China, the logistics economy in China is characterized by not high level, short emerging time, unreasonable layout and serious imbalanced development. Therefore, in the process of developing logistics economy, it has become the urgent problem to solve to scientifically and reasonably organize and allocate the logistics elements. Based on the regional movement rules, characteristics and rule of logistics elements, it is found that the logistics element of China is in a development stage of taking the agglomeration as the core. Therefore, when organizing the elements of logistics economy, it is required to adopt the mode of point-axis-network-plane. In this way, it is able to scientifically and reasonably arrange the elements of logistics economy and make fully use of the leading role of logistics to economy, so as to promote the development of regional economy.

\section{Point: central logistics cities}

For the elements of logistics economy, during agglomeration, generally the point agglomeration method will be adopted, while during diffusion, there will be a radiation state. Generally, the logistic activity mainly consists of warehousing, distribution. Although logistics activity is inseparable from transportation, various infrastructures to realize the logistics activity are mainly centered in the urban areas, which makes the logistics activity take cities as the main gathering places. From the micro aspect, when conducting spatial allocation to the elements of logistics economy, it is required to reduce the density of logistics in the cities and pay attention to the development of surrounding areas. Only in this way can the diffusion and agglomeration roles of logistics elements be played; from the macro aspect, when developing the logistics economy, it is required to place fewer focuses on the cities, use the scale effect of logistics economy during agglomeration of logistics economy to promote the formation of growth pole, make full use of the driving role of logistics economy, and further develop the economy of regional hinterland through logistics activity, so as to form the economic development circles.

\section{Axis: logistic economy zone}

Generally, during agglomeration of logistics economy, in addition to the point agglomeration way, the belt agglomeration will also be adopted, while the main diffusion way is belt radiation in the corresponding way. Generally in region, the elements of logistics economy often presents the objective and directional agglomeration, i.e. the logistics economy is linearly agglomerated toward a certain direction, so as to form the corresponding line zones, and for the natural and social factors, in the process of agglomeration, the logistics elements should interplay and interact with other elements, and combine with them to form a axis with relative property. For the surrounding logistics economy activity, this axis should have the corresponding agglomeration and radiation role. In general, during the agglomeration of logistics elements, the scope of agglomeration is sure to be controlled in a region of linear distribution. In this way, it is able to form linear region with the diffusion and agglomeration as the main core, so as to make full use of the effect of logistics economy activity on the economy, which can promote the further perfection of relevant infrastructures while driving the development of the surrounding economy.

\section{Network: logistics network}

From the micro aspect, as a senior diffusion way of logistics elements, network can further promote the development of logistics economy. During agglomeration, the logistics economy often present a composition of combination of belt with line. In this way, it is able to enhance the diffusion effect of logistics elements effectively, so as to result in the homogenization and densification; from the macro aspect, further expanding the scale of logistics economy zone and the central logistics cities can enhance the mutual connection between the two and promote the formation of logistics network. Therefore, when carrying out spatial configuration to the logistics elements, be sure to comply with the development law, select the regions with relatively advantageous regions, and when organizing the space, it is required to take the existing infrastructures and transportation network of such regions as the basic condition, so as to realize the network diffusion and agglomeration to the logistics economic activities.

\section{Plane: logistics circle}


For the logistics economy, as a plane of development, logistics circle is the senior stage of spatial structure development of the logistics economy, integrating many diffusion and agglomeration forms, and during the movement of logistics elements, they are not only toward the same direction, but will mot toward many directions, so as to realize the homogenization of logistics elements in regions. From the macro aspect, connecting the logistics economic zone with the central cities cannot only further perfect the logistics network, but can also make full use of the driving role of the logistics economic activity and drive the economic development of the undeveloped regions of the surrounding network, so as to promote the formation of logistics circle. Besides, when organizing the logistics economy spatially, it is required to take network as the basic condition, further enhance the diffusion and agglomeration of these regions, so as to realize the homogeneous allocation of the regional logistics economic elements.

\section{Conclusion}

In a word, with the continuous development of Chinese economy, the logistics economy faces new challenge while obtaining the development opportunities. Therefore, for the logistics economic activity, when allocating the space, be sure to use four modes, i.e. logistics network, central logistics cities, logistics circle and the logistics economic zones to make full use of the diffusion and agglomeration role of the logistics economic elements, and it is also required to promote the formation of spatial structure dominated by the logistics elements. Meanwhile, it is also required to fully mine many properties of the logistics elements, and use their characteristics to further enhance the further combination with many natural and social elements, promote the formation of various element complexes and realize the evolution of economic spatial structure, so as to further promote the development of Chinese logistics economy.

\section{References}

[1] Xu Qingbin, Guidance to Transportation Economics, Beijing: China Railway Publishing House, 2000

[2] Lu Dadao, On the Best Structures and Best Development of Regions, Journal of Geographical Sciences, 2001 (2): 27-135

[3] Han Zenglin, Wang Chengjin, Discussion on Characteristics and Layout of Chinese Logistics Industry and Their Countermeasures, Progress in Geography, 2002 (1): 336-341

[4] Lu Yuqi, Discussion on Dual-core Spatial Structure Mode, Research and Development of the Region, 1998 (4): 67-71

[5] Cui Gonghao, Regional Analysis and Planning, Beijing: Higher Education Press, 1999

[6] Zeng Juxin, Spatial Economy: System and Structure, Wuhan: Wuhan Press, 1996

[7] Chen Cai, Regional Economic Geography, Beeijing: Science Press: 2001

[8] Wang Chengjing, Spatial Organizaiton Pattern of Chinese Logistics, Economic Geography, 2005 (5): 366-368 